\title{
Measurements of Radon Concentration in Water of Campus, Dormitory and Student Home in South Area of Gifu Prefecture and Northwest Area of Aichi Prefecture
}

\author{
Michikuni Shimo, ${ }^{* 1}$ Masato SugInO*2 and Harumi Hatano*3
}

(Received on August 11, 2003)

(Accepted on August 25, 2003)

\begin{abstract}
KEY WORDS: measurement, liquid scintillation method, radon in water, city service water, well water, effective dose
\end{abstract}

\section{INTRODUCTION}

There is much data on the ${ }^{222} \mathrm{Rn}$ concentration in water $^{1-9)}$, especially in hot springs in Japan because wide surveys for finding radioactive springs have been performed over the past 100 years. The main aim of many surveys which were performed several decades ago was also to find hot springs, but some of these data were analyzed from a geologic standpoint, therefore useful knowledge for behavior of groundwater has been obtained ${ }^{1)}$. Recently, some researchers obtained ${ }^{222} \mathrm{Rn}$ concentration in famous spring water named Hyakumeisui (famous 100 springs for drinking) of $\mathrm{Japan}^{5}$. However, not so much data on domestic water, river water, ground water etc has been obtained. On the other hand, the human effects from radioactive materials in natural water have been considered less than in atmospheric air up to this time, and a dose evaluation of tap water in public has not been performed in Japan.

The dose from natural radiation is the main part of the total dose in public. In doses from natural radiation, the radon (including ${ }^{222} \mathrm{Rn},{ }^{220} \mathrm{Rn}$ and their decay products) contributes over fifty percent. Radon in drinking water as well as in atmospheric air affects the dose and the authors think that it is important to know the radon concentration in water. In this survey we measured radon concentration

${ }^{* 1}$ School of Health Sciences, Fujita Health University; 1-98, Dengakugakubo, Kutsukake-cho, Toyoake-shi, Aichi 701192, Japan.

*2 Medical College of Gunma Prefecture; 323-1, Kamioki-cho, Maebashi-shi, Gunma 371-0052, Japan.

*3 Saiseikai Sanjou Hospital; 6-18, Ohnohata, Sanjo-shi, Niigata 955-0833, Japan. in drinking water sampled on a campus, in dormitories and in student homes, and a rough estimation of student dose from radon in water was performed.

\section{MEASUREMENTS}

\section{Instrument}

The liquid scintillation method was used for performing the survey. In recent times the most widely used method for determining ${ }^{222} \mathrm{Rn}$ levels in water uses a toluene-based liquid scintillator. This method was first initiated by Noguchi ${ }^{10}$ and thereafter the method was established as being an expedient method.

The detection limit of this instrument is nearly 0.1 $\mathrm{Bq} / \mathrm{L}^{11)}$.

\section{Concentration Calculation}

In the liquid scintillation method, ${ }^{222} \mathrm{Rn}$ concentrations were calculated from the count value at the time of collection of the sample water using the following formula. If the ${ }^{222} \mathrm{Rn}$ concentration in sample water is expressed by $Q[\mathrm{~Bq} / \mathrm{L}], Q$ is presented by the formula

$$
Q=\frac{C-C_{0}}{5 \varepsilon \cdot \mathrm{V} \cdot \mathrm{T}} \cdot f
$$

where $\quad C$ : Count of 5 minutes extrapolated to the time of sampling;

$C_{0}$ : Background count;

$\varepsilon$ : Counting efficiency (1.0);

$V$ : Sample volume [L] $(0.180 \mathrm{~L})$;

$T$ : Counting time $[\mathrm{s}](300 \mathrm{~s})$

$f$ : Correction factor obtained from calibration.

" 5 " in $5 \varepsilon \cdot \mathrm{V} \cdot \mathrm{T}$ is the number of $\alpha$-rays and $\beta$-rays coming out of ${ }^{222} \mathrm{Rn},{ }^{218} \mathrm{Po},{ }^{214} \mathrm{~Pb},{ }^{214} \mathrm{Bi}$ and ${ }^{214} \mathrm{Po}$ with the measurements made under the condition that ${ }^{222} \mathrm{Rn}$ and its 


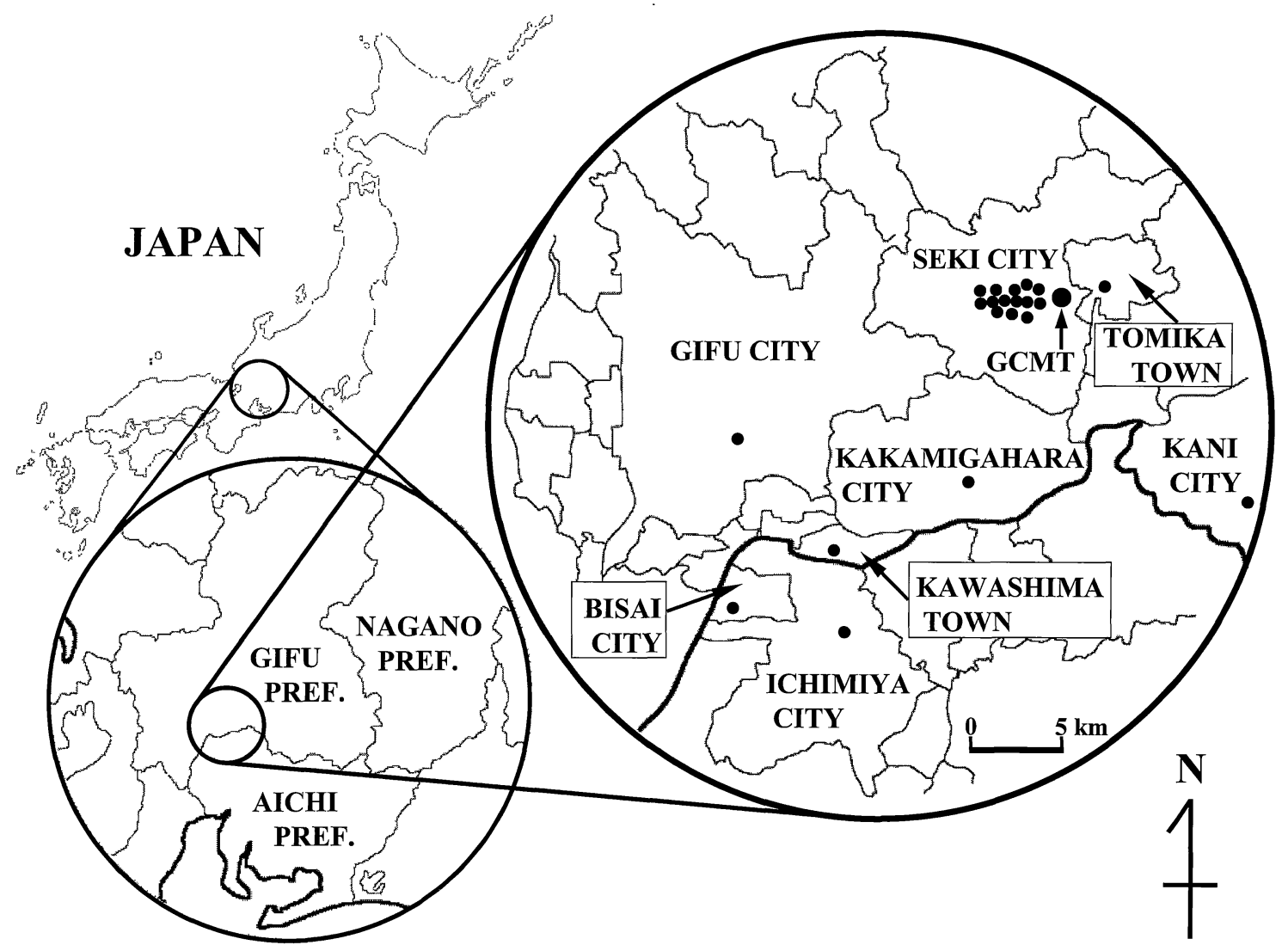

Fig. 1 A map of sampling location; large closed circle shows GCMT and small closed circle does sampling point of water.

decay product nuclides are in radioactive equilibrium. The sample preparation and measurement conditions were shown in brackets. Calibration of the liquid scintillation counter was made by a secondary calibration method in which one sample is mutually measured using two counters. The other counter used for this calibration was an already calibrated liquid scintillation counter (Aloka-602) belonging to the School of Engineering, Nagoya University. Finally, the value of $f$ was decided as 1.92 .

Introducing figures of $\varepsilon, V, T$ and $f$ to formula (1), the following formula is obtained for calculating radon concentration from counts in 5 minutes.

$$
Q=0.0071\left(C-C_{0}\right)
$$

\section{Water Sampling and Measurement}

Sampling was mainly performed in Seki city, Gifu prefecture and its surrounding area which is shown in Fig. 1. Sample waters were obtained from the buildings of a campus, dormitories and student homes at various times. Over $500 \mathrm{~mL}$ of water from a faucet was directly contained into plastic bottles and immediately corked tightly. Plastic bottles filled with sample water were brought to the laboratory and measuring vials made from sample water were carefully prepared in a time period varying from half an hour to several hours after sampling.
Five-minute-measurement was continued intermittently during about 10 days and radon concentration was estimated from the decay curve obtained from measurements.

Incidentally, it must be noted that the ambient and water temperature, pressure and compounds in the sample water were not evaluated. It is understood that these factors have an effect on variation of the ${ }^{222} \mathrm{Rn}$ concentration in water. We noted only atmospheric temperature and pressure at the time of sampling.

\section{Reliability of Measurements}

It is guessed that the largest cause for the uncertainty in data is in difference of the condition of sampling way of water. In this study, the water samples were taken by many students, and of course they were briefly trained before sampling action. Their sampling techniques, however, were poor and several parts of radon in water may be released from water. Data listed in the paper were carefully checked upon before adoption of sample, but it would be possible to take wrong data. In this case, measurement value may be several ten percent lower than true value.

On the other hand, the error also includes the counting error and the error from deviation of sample vials (ordinarily, 2-3 vials made). In this case, a margin of error of about $6 \%^{11)}$ was expected in measurements. 


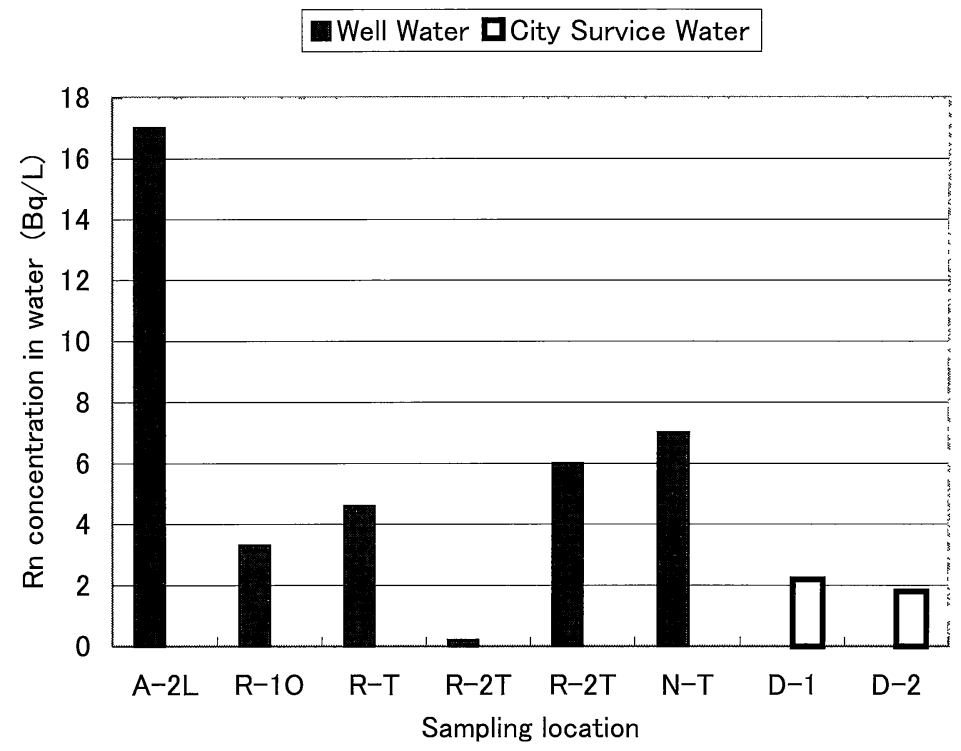

Fig. 2 Radon concentrations of water sampled in building of campus. D-1 and D-2: city survice water, others: well water.

Well Water $\square$ City Survice Water

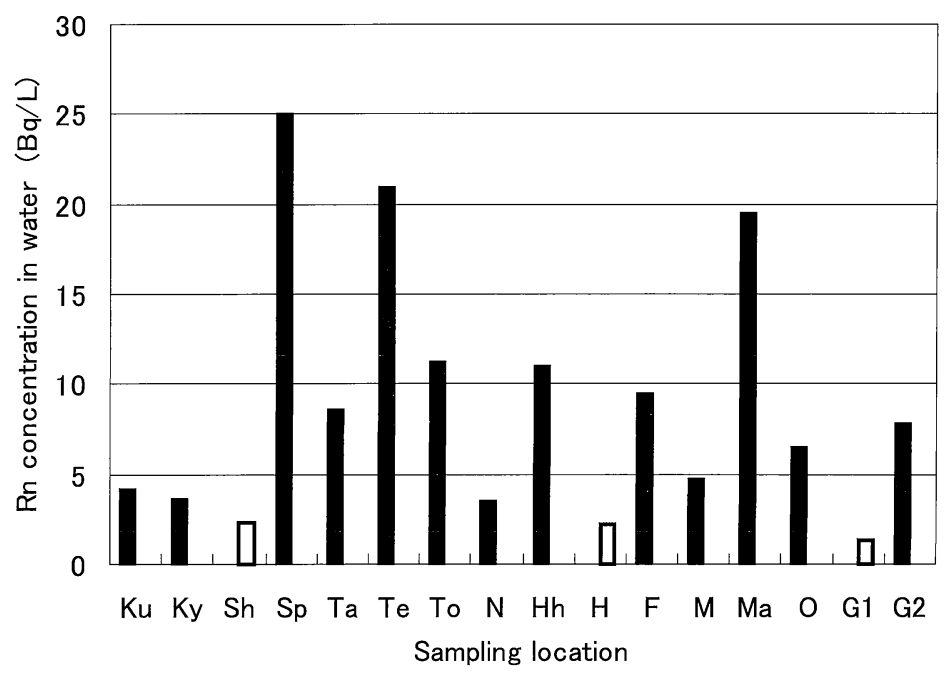

Fig. 3 Radon concentration in water sampled at dormitories. Sh, H and G1: city survice water, others: well water.

\section{RESULTS AND DISCUSSION}

\section{Radon Concentration in Water on Campus}

The data in Fig. 2 were obtained on the campus of Gifu College of Medical Technology (GCMT) located in Seki City. The water was taken from the faucets of several auditorium rooms and laboratories. The campus waters are provided by both city service water and well water, and the two types of water are not mixed. The ${ }^{222} \mathrm{Rn}$ concentration from well water was somewhat higher than that of the city service water. An interesting thing was also noted from the "R2L" data in Fig. 2, which shows a very low ${ }^{222} \mathrm{Rn}$ concentration in spite of it being well water. This was found to be because the faucet in the room had not been used for almost 3 weeks, which was 5.5 times the half-life of ${ }^{222} \mathrm{Rn}$. The authors concluded that ${ }^{222} \mathrm{Rn}$ in that faucet water must have decayed beyond its half-life and thus become almost "radon-free" water. Other faucets had been used frequently every day.

\section{Radon Concentration in Water in the Dormi-} tories

Figure 3 shows ${ }^{222} \mathrm{Rn}$ concentrations obtained in potable water in several dormitories and student homes around the college (GCMT), and shows a wide variation; 2.0-25 Bq/L. Water samples were generally taken 
Local mean time

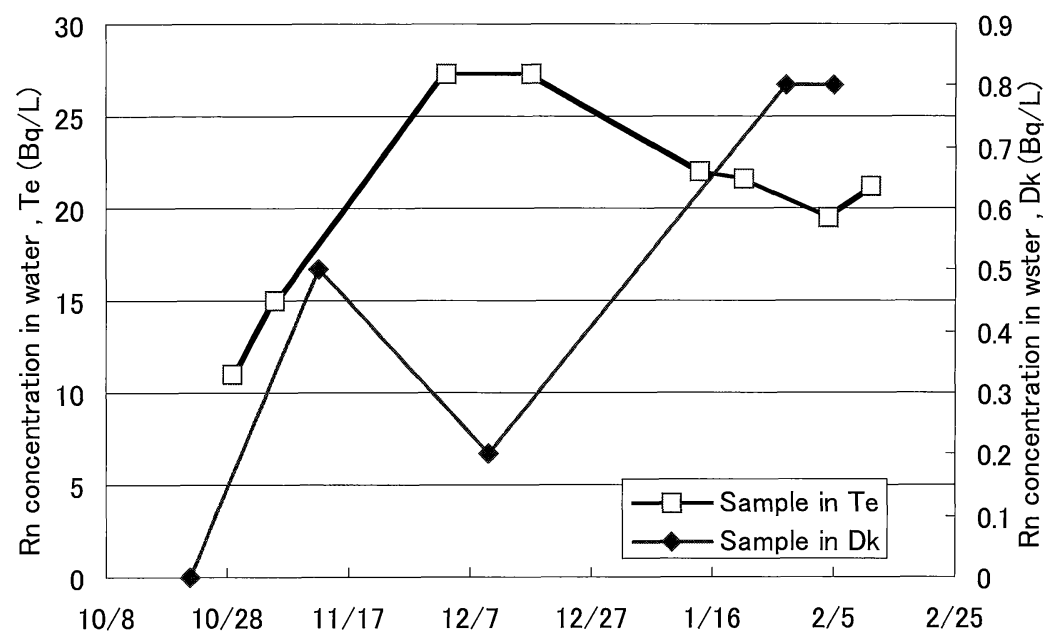

Fig. 4 Radon concentration in water sampled at two typical dormitories.

Table 1 Radon concentration in domestic water in student home in several cities.

(unit: $\mathrm{Bq} / \mathrm{L}$ ).

\begin{tabular}{|l|c|c|c|}
\hline \multicolumn{1}{|c|}{ City/Town } & Source & No. & ${ }^{222} \mathrm{Rn}$ \\
\hline Gifu City, Gifu Pref. & C.W. & 1 & 7.7 \\
Seki City, Gifu Pref. & C.W. & 2 & $0.93-2.5$ \\
& Well & 12 & $3.5-28$ \\
Kawashima Town, Gifu Pref. & Ukn & 1 & 0.93 \\
Tomika Town, Gifu Pref. & C.W. & 3 & $0-0.30$ \\
& Well & 1 & 2.4 \\
Kani City, Gifu Pref. & C.W. & 1 & 1.7 \\
Kakamigahara City, Gifu Pref. & G.W. & 1 & 2.3 \\
Bisai City, Aichi Pref. & C.W. & 1 & 6.6 \\
Ichimiya City, Aichi Pref. & C.W. & 1 & 7.4 \\
\hline
\end{tabular}

No.: number of sample, C.W.: city survice water, G.W.: ground water, Ukn: unknown.

between 7:00-9:00 am. The dormitories and student homes are located in a narrow area of $2 \mathrm{~km}^{2}$ near the college. Some of the dormitories and student homes have well water while others have city service water. Several homes have both types of water, which have not been mixed.

The authors were unable to confirm the origin of the water for these samples, as they were unable to contact all the inhabitants. It was suspected that the difference between the two types of water therefore was not huge because well water and city tap water on campus were of the same value.

Figure 4 shows the time variation in two of the dormitories; one was obtained from the city service water (Dk) and the other from well water $(\mathrm{Te})$. The concentration for the dormitory $\mathrm{Te}$ is higher than that for the dormitory $\mathrm{Dk}$, and the difference in concentrations between the two is very clear. The dormitory $\mathrm{Te}$ was located far from the central city and it takes a long time for city service water to be carried from the water supply source to the dormi- tory. In addition, it seems that radon in well water varies according to time. These facts call us attention about how to take ${ }^{222} \mathrm{Rn}$ concentration in drinking water.

\section{Radon Concentration in Student Homes}

Table 1 shows the results of measurements carried out continuously for half a year in Seki City, Gifu Prefecture, and the peripheral area including Seki, Gifu, Kakamigahara and Kani Cities, Kawashima and Tomika Towns; and Ichinomiya and Bisai Cities in Aichi Prefecture, which are students' home cities and towns. ${ }^{222} \mathrm{Rn}$ was significantly detected in almost measurements except only one.

In these cities and towns, some houses use city service water and others well water. In general circumstances, city service water in big cities in Japan is normally supplied from rivers. Some cities use the mixed water of both river and well waters. After measurements were made it became clear that ${ }^{222} \mathrm{Rn}$ sometimes existed even in city service water. This makes the suggestion to us that water is sent to each faucet of a building or house from the source in 
a fairly short period of time. The fact shows that it is important to survey ${ }^{222} \mathrm{Rn}$ concentration in city service water in case of watch of ${ }^{222} \mathrm{Rn}$ in drinking water. The data obtained in well water were same value in contract in other data in $\mathrm{Japan}^{4,5,12)}$. The geology of the area where water was sampled is not so special as compared with other area. In addition, bedrock in the area is sedimentary rock or alluvial soil, therefore it is thought that radon concentration in the area is not so high such as in granite zone.

\section{Brief Estimation of Exposure from Radon in Water}

Radon in tap water may result in exposure from the ingestion of drinking water and from the inhalation of radon released from water to air when water is used indoors. Therefore, exposure from radon in water was roughly estimated using the obtained data. The release of radon gas from water to air $\left(10^{-4}\right)^{13)}$ and the inhalation dose coefficient $\left(2.3 \mathrm{nSv} /\left(\mathrm{Bq} \cdot \mathrm{h} \cdot \mathrm{m}^{-3}\right)\right)$ were shown in the UNSCEAR 1993 Report $^{14)}$. Ingestion of tap water (50 $\mathrm{L} / \mathrm{y}$ ) and the ingestion dose coefficient ( $3.5 \mathrm{nSv} / \mathrm{Bq})$ was evaluated in another reference ${ }^{13)}$. In the case of inhalation, the maximum exposure from radon in water was estimated as $0.006 \mathrm{mSv} / \mathrm{y}$ in school (used data: ${ }^{222} \mathrm{Rn}$ concentration of $17 \mathrm{~Bq} / \mathrm{L}$ and annual occupancy time of 1,500 hours), and $0.034 \mathrm{mSv} / \mathrm{y}$ at home $\left({ }^{222} \mathrm{Rn}\right.$ concentration: $28 \mathrm{~Bq} / \mathrm{L}$ and annual occupancy time: 5,500 hours). Thereupon, an annual occupancy time of 1,500 hours was estimated from school-hours and another occupancy time of 5,500 hours was obtained from subtracting 1,500 from 7,000 , which was indoor occupancy time. Therefore, the total dose of inhalation was $0.040 \mathrm{mSv} / \mathrm{y}$ and this is considered to be an upper value. In the case of ingestion, the maximum exposure was also estimated as $0.0006 \mathrm{mSv} / \mathrm{y}$ in school and $0.0037 \mathrm{mSv} / \mathrm{y}$ at home, and total exposure was estimated to be $0.0043 \mathrm{mSv} / \mathrm{y}$ by using the same radon concentration and occupancy time. The total maximum effective dose from radon in water is thus 0.044 $\mathrm{mSv} / \mathrm{y}$, and it seems that the actual dose is below this value. In addition, the estimated value is roughly 10 percent or less than the dose due to the inhalation of ${ }^{222} \mathrm{Rn}$ and its decay products in air.

Needless to say, the effective dose from radon in water mentioned above is not representative in Japan and is trial calculation from limited data. The authors suggest carefully that the dose from radon should be estimated by data of radon in both air and water and that survey of radon in drinking water should be widely carried out.

\section{CONCLUSION}

Measurement of radon concentrations in water on campus, in dormitories and in student homes was performed using a liquid scintillation counter. ${ }^{222} \mathrm{Rn}$ concentrations in water were $2.0-17 \mathrm{~Bq} / \mathrm{L}$ for campus, $0-27 \mathrm{~Bq} /$ $\mathrm{L}$ for dormitories, and $0-7.7 \mathrm{~Bq} / \mathrm{L}$ for student homes. The results show that the difference is slight among different sample sources. On the other hand, the tendency is clear that ${ }^{222} \mathrm{Rn}$ concentration was lower in service water than in well water; ${ }^{222} \mathrm{Rn}$ concentrations of city service water and well water were $0-7.7 \mathrm{~Bq} / \mathrm{L}$ and $2.3-27 \mathrm{~Bq} / \mathrm{L}$, respectively. The results mean that city service water in the area includes some ${ }^{222} \mathrm{Rn}$. The annual effective dose from radon in water was estimated equal to or less than 0.044 $\mathrm{mSv}$.

\section{Acknowledgment}

The authors wish to express their thanks to the students of Gifu College of Medical Technology for sampling the raw water and performing the measurements.

\section{REFERENCES}

1) K. Horiuchi; Radon in natural water, Proc. of the 7th Tohwa University International Symposium, "Radon And Thoron in The Human Environment", A. Katase and M. Shimo (eds), pp. 465-473 (1997).

2) K. Horiuchi and Y. Murakami; Basic studies on the new determination method of radon in mineral springs with a liquid scintillation counter, J. Balneol. Soc. Jpn., 28, 39-52 (1977).

3) Radon Observation Team, Spa and Earth Science Institute; Report, Kanagawa Prefecture Spa and Earth Science Institute, No. 13, 99-108 (1982).

4) S. Ohnuma, K. SATO and K. ChayA; Distribution of radon concentrations in ground water in Aichi Prefecture, M. Shimo and T. Tsujimoto (eds) "Environmental Radon", pp. 140-149 (1992).

5) T. IsHII and K. HoRIUCHI; Radon in natural water, M. Shimo and T. Tsujimoto (eds) "Environmental Radon", pp. 160-166 (1992).

6) S. ShibAtA, K. KAWANO and R. Ito; The estimation of radon contents in ground water by using TL-SLC method. M. Shimo and T. Tsujimoto (eds) "Environmental Radon", pp. 341-348 (1992).

7) R.C. Ramola, R.B.S. Rawat, M.S. Kandari and V.M. CHOubeY; Measurement of radon in drinking water and indoor air, Radiat. Prot. Dosimetry, 74, 103-105 (1997).

8) C.H. MAO and P.S. WenG; Radon concentration in Neitaping Cold Spring, A. Katase and M. Shimo (eds), Proc. of the 7th Tohwa University International Symposium, "Radon And Thoron In The Human Environment", pp. 474-479 (1997).

9) Y. Chen, W. Qun, Z. Bo and D. Chen; Radon concentrations in well water in Sichuan Province, China, A. KatAse and M. SHImo (eds), Proc. of the 7th Tohwa University International Symposium, "Radon And Thoron In The Human Environment", pp. 480-484 (1997).

10) M. NoguchI; New method of radon activity measure- 
ment with liquid scintillator, Radioisotopes, 13, 362 366 (1964).

11) M. SHIMo; Radon measurements in water using liquid scintillation counter, Memoirs of Gifu College of Medical Technology, 11, 23-30, 1995.

12) M. SHIMO; Measurements of radon concentration on domestic water and in river water, Proc. of the 5th Low Level Counting Conference Using Liquid Scintillation Analysis, pp. 36-44 (1996).

13) National Research Council; "Risk Assessment of Radon in Drinking Water", (1998), National Academy Press, Washington, D.C.

14) United Nations Scientific Committee on the Effects of Atomic Radiation; Sources and effects of ionizing radiation, 1993 Report to the general assembly, with annexes, United Nations Sales Publication E.94.IX.2, United Nation, New York (1993).

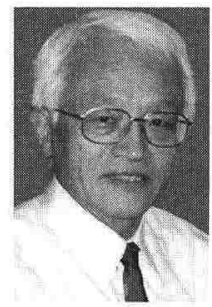

\section{Michikuni SHIMo}

Professor, School of Health Sciences, Fujita Health University. Specialty: environmental radioactivity, mainly, survey and dose estimation on radon and its decay products. President of Japan Health Physics Society. 